\title{
OCCUPATIONAL ASPECTS OF WORK IN HYPOXIC CONDITIONS - THE NEW RECOMMENDATION OF THE MEDICAL COMMISSION OF THE UNION INTERNATIONALE DES ASSOCIATIONS D'ALPINISME (UIAA MEDCOM)
}

\author{
Thomas Küpper ${ }^{1,2}$, Jim S. Milledge ${ }^{2,3}$, David Hillebrandt ${ }^{2}$, Jana Kubalova ${ }^{2,4,5}$, Urs Hefti $^{2,6}$, Buddha Basnayt $^{2,7}$, \\ Ulf Gieseler ${ }^{2}$, Suzanne Arnold ${ }^{8}$, Volker Schoffl',9,10 \\ ${ }^{1}$ Institute for Occupational and Social Medicine, RWTH Aachen University, Aachen, Germany \\ ${ }^{2}$ Medical Commission of the Union Internationale des Associations d'Alpinisme (UIAA MedCom), Bern, \\ Switzerland \\ ${ }^{3}$ University College of London, U.K. \\ ${ }^{4}$ Emergency Medical Service, Jihlava, Czech Republic \\ ${ }^{5}$ Chairman of the Medical Commission of the the Czech Mountaineering Association \\ ${ }^{6}$ Kantonsspital, Department of Surgery, Aarau, Switzerland \\ ${ }^{7}$ Nepal International Clinic, Kathmandu, Nepal \\ ${ }^{8}$ Institute for Neuroanatomy, RWTH Aachen University, Aachen, Germany \\ ${ }^{9}$ Dept. of Sportorthopedics, Klinikum Bamberg, Germany \\ ${ }^{10}$ Dept. of Trauma Surgery, Friedrich Alexander University Erlangen-Nuremberg, Germany
}

\begin{abstract}
More and more persons are exposed to hypoxia while working at altitude, e.g. when working for cable cars or ski areas in the Alps, for business in South America or Asia, as airline crews, or in rooms with reduced oxygen pressure for hypoxia training or fire protection. Unfortunately, the different countries have a multitude of regulations for occupational health and safety concerning hypoxia - most of them with major deficiencies and a significant lack of knowledge about hypoxia and possible specific risks. So far, no national regulation differentiates the different types of hypoxia and the environment, both having significant influence on the specific risk profile of employees and consequences for occupational health and safety.

As the world's umbrella body for preventive medicine at altitude / hypoxia, the Medical Commission of the Union Internationale des Associations d'Alpinisme (UIAA MedCom) recently established a recommendation to enable the national bodies to establish knowledge-based pragmatic procedures for occupational health and safety [1]. The most important message is as follows: Any environment with oxygen concentration of $14.0 \%$ or more or an altitude of $3,000 \mathrm{~m}$ or less is safe for any non-acclimatized person without severe cardiopulmonary disease (<NYHA III or CCS III), without severe anaemia (Hb $>10$ $\mathrm{g} / \mathrm{dl}$ ) and an exposure limited to a few hours (one work shift). These environments include most alpine cable cars, ski areas, aircrafts flying on long-range distances, most towns or villages where businessmen might go to, and rooms for fire protection. For longer exposure (sleep at high altitude) or higher environments the persons should be acclimatized or exposed for a short time only. Details how to manage health and safety in such environments are given.
\end{abstract}

Key words: hypoxia, occupational medicine, occupational safety, workload

\section{Introduction}

Apart from "classical" hypoxia, which is almost an exclusive problem for mountaineers, workers at cable cars, in ski areas or for mountain rescue services and, to lesser extent, for travelling businessmen, hypoxia is now also being used for fire prevention in storage areas, for altitude training in sport and for many other purposes. As a consequence more and more employees are exposed to hypoxia. Although there are no data, how many persons are exposed by their occupation, the total number should be estimated to be some hundred thousands as there are more than 10,000 members of the German mountain rescue service ("DRK Bergwacht") only [2]. Up to now there has been no consensus on how to provide occupational health and safety advice. Most regulations do not take into account the kind of exposure or other circumstances (e.g. whether the person is able to "escape" from hypoxia at any time). Regulations do not consider the type or degree of different risks - if any - and therefore a more detailed analysis of the individual kind of exposure is necessary to provide adequate advice for health and safety. 
The U.K. guidelines of "Safe Work in Confined Spaces" [3] were not written for hypoxia caused by controlled isobaric gas mixtures or hypobaric hypoxia at altitude, but for "enclosures with limited openings" like storage tanks, silos etc. The recommendation to use self-containing breathing apparatuses if "a lack of oxygen" (no definition given!) can be assumed results from hypoxia in such environments (toxic gases) and is not appropriate for hypobaric or isobaric hypoxia as discussed here. Other papers, e.g. the so-called "Bath Report" ignore that the symptoms may start not before 6-8 $\mathrm{h}$ at an altitude of about 2,500-2,700 $\mathrm{m}$ which is discussed in the text. Often these symptoms occur even much later $(>24 \mathrm{~h})$ and therefore the employees finish their daily work long before that may happen [4-8]. At this altitude (corresponding to $15 \% \mathrm{O}_{2}$ in isobaric conditions) the decrease of performance is only $10-12 \%$ while the cardiovascular strain is increased for about $+12 \%$ - a fact which is principally known since more than 140 years [9-13], and which can be neglected for most types of work. The U.K. Fire Protection Association recommends "Health assessments for individuals who will be working in a low oxygen atmosphere environment should be made for full time strenuous work in a $15 \%$ low oxygen atmosphere environment, full time work in a $13 \%$ low oxygen atmosphere environment. The health assessment is not necessary if the oxygen concentration will be $17 \%$, where the exposure will be less than 2 hours per day" [14].

The Austrian Government requires a medical check for any person working at $<17 \%$. Obviously the main argument is that German regulations do the same and the Swiss regulations require a medical check at $<18 \%$ (E. Szymanski, letter dated 19.3.09), neglecting Burtscher who is cited in the letter stating that $15 \%$ $\mathrm{O}_{2}$ is generally accepted as being without risk for anybody without a severe disease. This is proven by more than 4 billion people per year who are exposed to such hypoxia as aircraft passengers and for other reasons $[15,16]$ and by billions of smokers with a CO haemoglobin concentration of 5\% that corresponds to hypoxia of about $15 \%$. An increased risk for altitude- respectively hypoxia-related disturbances arises above $3,000 \mathrm{~m}\left(<14.5 \% \mathrm{O}_{2}\right)$ for persons without severe pre-existing diseases $[15,17]$.

Germany and some other European countries follow the so-called "LASI paper" [18]. Many statements given there ignore standard literature of hypoxia or altitude medicine: In contrast to the LASI paper there are many papers and data about intermittent hypoxia - and even more: data suggest that intermittent hypoxia of moderate degree has some benefit instead of risk for persons being regularly exposed, as there is an amelioration of the lipid profile, insulin resistance, leptine regulation, body weight, and others (e.g. [19-26]).
So far, the most advanced and detailed recommendation is the Swiss one [27]. Taking the risk into account it is recommended to use self-containing breathing apparatuses at $<13 \% \mathrm{O}_{2}$ (for non-acclimatized persons). The maximum permanent stay in hypoxic atmosphere is $4 \mathrm{~h}$ at $>15 \% \mathrm{O}_{2}, 2 \mathrm{~h}$ at $<15 \%$ $\mathrm{O}_{2}$ and with a daily maximum of $6 \mathrm{~h}$. This takes the dynamics of AMS symptoms at different altitude into account. A very pragmatic approach is given for occupational medicine to exclude relevant diseases and to clarify the risk of any diagnosis found.

\section{Types of occupational exposure to hypoxic condi- tions}

With regard to the current discussion it should be emphasised that mild or moderate hypoxia is normally not a risk. Five important factors must be taken into account for the differentiation and the risk profile of exposure to hypoxia:

- Altitude or equivalent altitude $\left(\% \mathrm{O}_{2}\right)$, respectively

- Duration of exposure

- Altitude profile/acclimatization (intermittent hypoxia included)

- Workload in hypoxic condition

- Native highlanders vs. native lowlanders

With the five major points given above at least four kinds of exposure each with a completely different risk profile can be established (Fig. 1). The individual risk profile must be taken into account for any procedure in health and safety at work.

Extreme short exposure normally takes place at altitudes between $1800 \mathrm{~m}$ and $2500 \mathrm{~m}$ and for some minutes to some hours. With isobaric hypoxia of about 17.0-14.8\% $\mathrm{O}_{2}(+/-0.2)$ in rooms equipped with hypoxia systems for fire prevention, exposure of employees is equivalent to an altitude of about 1,700-2,600 m. This altitude is well within the range of the so-called "threshold altitude", which is the altitude, where the body shows the first responses to hypoxia. Depending on the system observed, the threshold altitude varies between $1,500 \mathrm{~m}$ (slight increase in pulse rate at rest) to 2,400 $\mathrm{m}$ (increase of erythropoietin serum concentration) [28, 29]. In conclusion altitudes around the threshold do not cause any risk for healthy people by hypoxia. It also does not cause risks for people with chronic diseases of moderate severity [30]. If employees are exposed to equivalent altitudes between $2,700 \mathrm{~m}$ and $3,800 \mathrm{~m}$ in rooms for fire protection, these situations are normally limited to a maximum of some hours, often for $<60 \mathrm{~min}$. As for any room equipped with hypoxia systems for fire protection these employees can leave immediately at any time if they do not feel well and should be advised to do so.

If the exposure is hypobaric the main problem is the change of pressure, especially in the case of infections of the upper airways. Here employees should be 


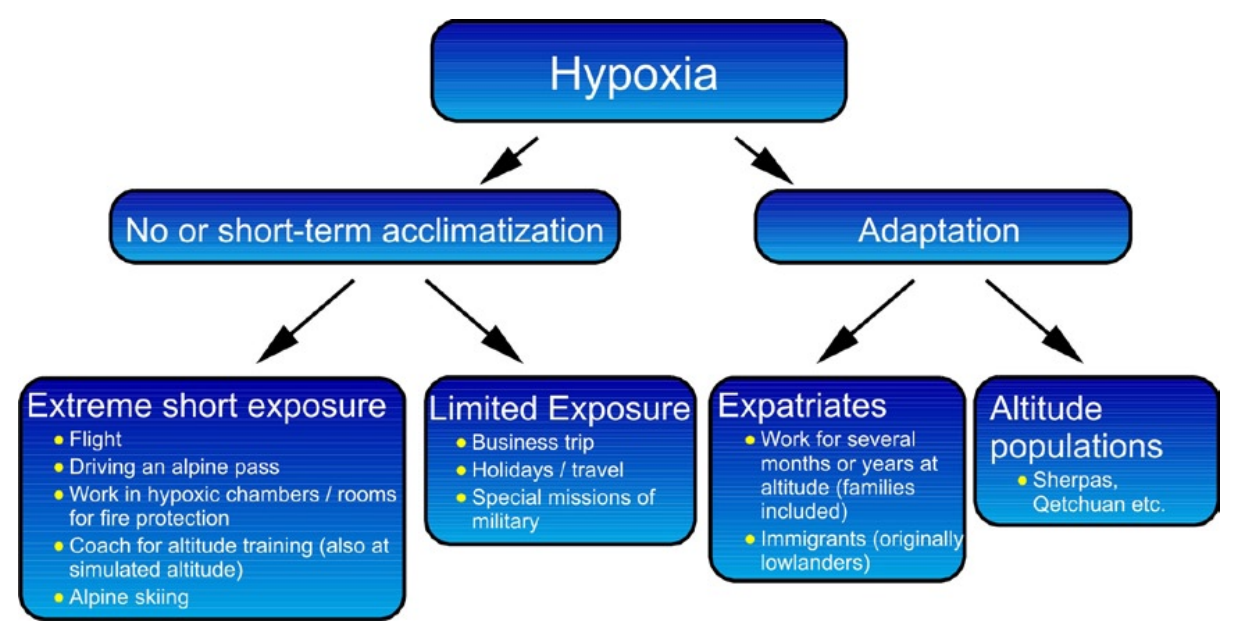

Figure 1. Different types of occupational exposure to hypoxic conditions

advised to use decongestant sprays and to take care for regular pressure pressurization of the ears ("ear clearing"). This is also the main problem for the longest exposure of this type ("extreme short exposure"): long distance flights. There are data that some airlines operate even higher cabin altitude than the limit of 2,400 m given by ICAO, especially when using modern aircraft [16]. Nevertheless, normally everybody - including pregnant women [31,32] and children [33] - will feel well at these altitudes.

There is a special subgroup: Persons who coach others, normally mountaineers, who pre-acclimatize for extreme altitude expeditions. This is increasingly used by facilities which offer rooms with isobaric hypoxia. This may expose participants to an altitude of $5,300 \mathrm{~m}$ or more $\left(10.5-11 \% \mathrm{O}_{2}\right)$. In most cases this exposure is limited to some minutes to up to half an hour. With the special advantage of isobaric hypoxia these employees can easily escape to normal atmospheric conditions at any time if they should feel unwell.

The typical exposure of the Limited Exposure Group is 2,000 to 3,000 m for some days or weeks. At some places these people will be exposed to even higher conditions of 4,000-5,000 $\mathrm{m}$. The combination of altitude and duration of exposure is potentially able to cause altitude disease (acute mountain sickness, AMS). High altitude pulmonary oedema (HAPE) is extremely rare at $2,000-3,000 \mathrm{~m}(1: 4,000$ nights at $3,000 \mathrm{~m}$ [34]) as it normally occurs above $4,000 \mathrm{~m}$. A significantly increased risk exists for any person who has a rapid ascent profile, e.g. businessmen travelling by aircraft. If the arrival destination is around $4,500 \mathrm{~m}$ the risk for HAPE with severe symptoms increases to 1:600 [34] (signs for HAPE in X-ray up to 31.7\% [35]) and $30-57 \%$ will suffer from AMS [5, 36-39]. These data indicate that some hours or even a night at 3,000 $\mathrm{m}$ is relatively safe, at least for healthy people.

Expatriates are defined as persons who migrate as lowlanders to high altitude regions, normally above $\mathbf{3 , 0 0 0 ~} \mathrm{m}$. Some of them are living higher than 4,500 $\mathrm{m}$. The duration may be for several months but is mostly for years. Normally this group will not suffer from acute altitude diseases (after the first few days at altitude) and they will fully acclimatize. In many cases the employees are accompanied by their families. As a consequence, pregnancy may be a problem [31] and children of different ages will be exposed to high altitude. After a while they may suffer from specific diseases of the cardiopulmonary system: high altitude pulmonary hypertension (HAPH) (formerly called sub-acute mountain sickness) with acute bouts of high blood pressure in the pulmonary vessels [40] and high altitude heart disease. For details see [33].

After some months at high altitude adults may develop symptoms of HAPH, caused by chronic pulmonary hypertension. These patients suffer from signs of insufficiency of the right ventricle (peripheral oedema, dyspnoea, cough, and angina pectoris). After years at altitude, chronic mountain sickness (CMS, "Monge's Disease") may arise (headache, poor concentration, dizziness, reduced work capacity, cyanosis, clubbed/drumstick fingers, polycythaemia and high haemoglobin concentration) [41-47].

Altitude populations are defined as populations living for several generations at altitude $>\mathbf{3 , 0 0 0} \mathbf{m}$. These people show long-term and genetic adaptations. Some of them may develop CMS (see above). Another specific problem is re-entry pulmonary oedema where highlanders and also expatriates or immigrants who visit friends or relatives near sea level are of special risk when they return to their high altitude home after a stay of a week or two at low altitude. The symptoms are the same as those for HAPE $[48,49]$.

\section{Occupational safety and health}

Minimal requirements given by aviation medicine should be used for moderate altitude too (values for sea level in adults) [50]: vital capacity 3 l, FEV1 70\%, $\mathrm{SaO}_{2}$ $85 \%, \mathrm{pO}_{2}$ art. $70 \mathrm{mmHg}$, haemoglobin $>10 \mathrm{~g} / \mathrm{dl}$ and erythrocyte count $>3$ million/ $\mu \mathrm{l}$ [50]. For exposure up to $2700 \mathrm{~m}\left(14.8 \% \mathrm{O}_{2}\right)$ a self-report that there is no significant disease of the cardiopulmonary system and no 
Table 1. Permanent or temporary contraindications for altitude sojourns of the "extreme short exposure group" as defined above (according to the recommendations for aircraft travellers) [50]

\begin{tabular}{|l|l|}
\hline \multicolumn{1}{|c|}{ Diagnosis } & \multicolumn{1}{c|}{ Period for which altitude / hypoxia should be avoided } \\
\hline Stroke & 3 months \\
\hline Myocardial infarction & 6 weeks, if no complications \\
\cline { 2 - 2 } & $\begin{array}{l}10 \text { weeks (or more) in the case of complications } \\
\text { (e.g. significant arrhythmia) }\end{array}$ \\
\hline Aortocoronary bypass operation & $2-3$ weeks \\
\hline PTCA & 3 days \\
\hline Stent & $3-10$ days \\
\hline Pace maker implantation & After a check for correct function is o.k. \\
\hline Acute broncho-pulmonary infections & No exposure until recovery \\
\hline Asthma (stress induced) & No exposure, if not sufficiently treated \\
\hline
\end{tabular}

epilepsy should be sufficient. If local regulations require a medical check-up this should focus on the person's history (any indicators for cardiopulmonary diseases or for significant limitations of maximum workload or sports? any significant disease or operations in the last year? any problems during altitude sojourns in the past? high or extreme workload at altitude expected?). If the person performs any aerobic endurance sport regularly and without problems, there is no doubt - without any other medical investigation - that there is no risk if this person is exposed within the conditions as described for the "extreme short exposure group" up to $2,700 \mathrm{~m}$ or about $15.0-14.8 \% \mathrm{O}_{2}$.

If employees are exposed to equivalent altitudes of $2,700-3,800 \mathrm{~m}$ as mentioned above, the medical procedure should additionally include blood count, ergometry and spirometry (as $\dot{\mathrm{VO}}_{2}$ max is the limiting factor at high altitude this may be combined as spiroergometry). Employees who go to $>3,800 \mathrm{~m}$ should be checked as detailed as for above 2,700-3,000 $\mathrm{m}$. Since hypoxic chambers are increasingly available these employees should be exposed to hypoxia once before their first departure to high altitude $3,500 \mathrm{~m}$ or before they enter hypoxic rooms for the first time (employees who do mountaineering may be excluded here). The exposure must take into account the kind, the expected duration, and especially the (equivalent) altitude $\left(\mathrm{pO}_{2}\right)$ of the exposure during work: During exposure the person should be monitored for $\mathrm{SaO}_{2}$, pulse rate, and altitude-related symptoms by persons with adequate skills in altitude medicine. Persons with cardiopulmonary diseases $>$ NYHA/CCS I, anaemic or pregnant persons should not be chosen for work at high altitude or hypoxia which corresponds to $>3,800$ $\mathrm{m}[30,31,51]$.

For a normal work day it is not necessary to include additional pauses, if the real or equivalent altitude does not exceed $2,700 \mathrm{~m}\left(\sim 14.8 \% \mathrm{O}_{2}\right.$ in isobaric conditions), as there is no risk for altitude-related disorders. If possible, and the work lasts all day in hypoxic rooms (e.g fire protection), the person should be advised to leave the hypoxic area for a lunch break. If non-acclimatized persons are exposed to equivalent altitudes of 2,700-3,800 $\mathrm{m}$ as mentioned above, they should be advised to make a pause in normoxia for at least 15 $\mathrm{min}$ after every $2 \mathrm{~h}$ of exposure. If they are exposed to $>3,800 \mathrm{~m}$, this pause should be extended to $30 \mathrm{~min}$. Non-acclimatized workers should avoid exposure to $>4,500 \mathrm{~m}$. Any employee should be advised to leave hypoxic areas if he / she does not feel well. To retreat to a normoxic area as soon as possible is the most important therapy in such a situation. If the symptoms recover completely after $1 / 4-1 / 2$ hour, the person can re-enter, if necessary. If the subject does not recover within $1 / 2$ hour he/she should be advised to consult a physician who is a specialist in altitude medicine before the next exposure.

Maximum workload needs not be investigated for all employees: If the work which has to be performed at altitude is not very hard (e.g. paperwork (businessmen), supervision etc.) and the altitude does not exceed 2,700 m, it is enough to know that the person is able to climb one flight of stairs or to walk $80-100$ $\mathrm{m}$ horizontal without shortage of breathing [51]. More detailed and according to NYHA / CCS stages [52-54]:

- NYHA / CCS I (no symptoms): No limitations at altitude

- NYHA / CCS II (symptoms during moderate workload): No limitations at altitude for activities of minor workload (business, supervision etc.).

- NYHA III-IV (symptoms during minimal workload or at rest): Contraindication for altitude. Diagnoses and situations which are a permanent or temporary contraindication are given in Table 1 . We also refer to the recommendations given in [30].

Persons who are exposed to extreme altitude e.g. while training expedition members must have a cardiopulmonary (especially pulmonary!) capacity well within the normal range. This may include also well 
treated asthmatic patients. Above 4,500 m employees should be observed for safety by a "rescue person" who is outside the isobaric hypoxia but in permanent contact to the person(s) inside. For optimum supervision rooms for isobaric hypoxia should be constructed with a big window to the next room or at least with a door of glass. Above $4,500 \mathrm{~m}$ safety may be further increased if an oxygen bottle and a mask is available. Above 4,500 $\mathrm{m}$ a specialist high altitude physician should be on call. Above $5,000 \mathrm{~m}$ he/she should be on scene.

In contrast to others of the "extreme short exposure group" employees working in such conditions need to be educated about symptoms and management of acute hypoxia. Again: if they work regularly in such conditions (e.g. every day 2-3x for 15-60 min, or even more) a benefit by partial acclimatization can be expected (although data are scarce).

For the Limited Exposure Group special attention should be paid to persons who might be suspected for obstructive sleep apnoea, as this is often combined with pulmonary hypertension. The latter will increase significantly at altitude. As mentioned above there is another risk for this group which cannot (yet) be predicted by any medical investigation: AMS. Here preventive occupational medicine includes detailed advice about the symptoms of AMS and how to treat them [48]. If possible discussion with the manager who is responsible for the employee and advice for an adequate ascent profile should be given [48]. This may include an extra day on arrival and an overnight stay at intermediate altitude. If an immediate ascent and overnight stay $>2,500 \mathrm{~m}$ cannot be avoided prophylaxis with drugs may be considered (acetazolamide $125 \mathrm{mg}$ bid, [48]). Any employee should be advised to contact an experienced high altitude physician immediately in the event that he / she does not feel well at high altitude and cannot descend. Painkillers, nifedipine, dexamethasone and acetazolamide with education and information on how to contact the physician to manage an emergency should be given to him / her before departure for any destination above $3,800 \mathrm{~m}$. Below $3,800 \mathrm{~m}$ a standard painkiller (not aspirin!) should be sufficient.

Before they leave, expatriates should get a more detailed medical examination, especially with electrocardiography and echocardiography included. This aims at two topics: i. to exclude pulmonary hypertension, and ii. to get initial values for a comparison with later controls as HAPH is the main risk for this group. A control echocardiography should be performed at least once a year or if symptoms should arise. Note that accompanying children need special attention [33]. If any pathologies which indicate increased pulmonary pressure or right ventricle hypertrophy or dilatation are found at echocardiography the patients should be advised to leave their high altitude residency as soon as possible.

\section{Conclusion}

A careful differentiation between the types of exposure enables those who are responsible for occupational health and safety to provide a specific strategy which includes both, safety and pragmatism, and is, therefore, an advantage for the employees as well as for the employers.

\section{References}

1. Kupper T, Milledge JS, Hillebrandt D, et al. Consensus Statement of the UIAA Medical Commission Vol.15: Work in Hypoxic Conditions. 2009 [cited 2009; Available from: www. theuiaa.org/medical advice.html.

2. Kupper T. Workload and professional requirements for alpine rescue. Professoral thesis at Aachen Technical University / Germany, 2006 (English publication in preparation). Dept. of Aerospace Medicine, Aachen Technical University. Aachen, 2006.

3. N.N. Work in Confined Spaces. London: Health and Safety Executive, 2005: 11.

4. Bartsch P. Das Höhenlungenödem: Epidemiologie, Klinik, Pathogenese und Therapie. In: Jenny E, Flora G, ed. Jahrbuch 1990, Innsbruck: Österreichische Gesellschaft für Alpin- und Höhenmedizin, 1990: 78-91.

5. Basnyat B. Acute mountain sickness in local pilgrims to a high altitude lake (4154 m) in Nepal. J Wild Med 1993; 4: 286-92.

6. Basnyat B, Murdoch DR. High-altitude illness. Lancet 2003; 361(9373): 1967-74.

7. Maggiorini M. Trekking und Höhenaufenthalt. Ther Umsch 2001; 58(6): 387-93.

8. Hackett PH, Roach RC. High-altitude illness. N Engl J Med 2001; 345(2): 107-14.

9. Bert P. La pression barométrique. Paris: Libraire de l’Académie de Médecine, 1878.

10. Glaisher J. Notes of effects experienced during recent balloon ascents. Lancet 1862; 2: 559-60.

11. Mosso A. Der Mensch auf den Hochalpen. Leipzig: Verlag von Veit \& Comp.; 1899.

12. Zuntz N, Loewy A, Müller F, et al. Höhenklima und Bergwanderungen in ihrer Wirkung auf den Menschen. Berlin: Deutsches Verlagshaus Bong \& Co, 1906.

13. Kellas AM. A consideration of the possibility of ascending Mount Everest. High Alt Med Biol 2001; 2(3): 431-61.

14. N.N. Low oxygen atmospheres and the risk control of associated health hazards. The Fire Protection Association. Gloucestershire/U.K.: Moreton in Marsh, 2005: 10.

15. Burtscher M. Gibt es eine medizinisch vertretbare Verträglichkeitsrenze für Sauerstoffmangel? Innsbruck, Austria: Inst. of Sport Science, University of Innsbruck, 2009: 15

16. Cottrell JJ. Altitude exposures during aircraft flight. Flying higher. Chest 1988; 93(1): 81-4.

17. Burtscher M. Endurance performance of the elderly mountaneer: requirements. limitations, testing, and training. Wien Klin Wochenschrift 2004; 116: 703-14.

18. Huke M, Heger M, Jansing $\mathrm{P}$, et al. Handlungsanleitung für die Beurteilung von Arbeiten in sauerstoffreduzierter Atmosphäre für die Arbeitsschutzverwaltungen der Länder LV 38 [Operational guidelines for the evaluation of work in oxygen reduced atmosphere for the Departments for Occupational Health and Safety of the federal states]. Länderausschuss für Arbietsschutz und Sicherheitstechnik (LASI). München: Bayerisches Staatsministerium für Gesundheit, Ernährung und Verbraucherschutz, 2005: 16.

19. Netzer NC, Chytra R, Kupper T. Low intense physical exercise in normobaric hypoxia leads to more weight loss in obese people than low intense physical exercise in normobaric sham hypoxia. Sleep Breath 2008; 12(2): 129-34.

20. Armellini F, Zamboni M, Robbi R, et al. The effects of high altitude trekking on body composition and resting metabolic rate. Horm Metab Res 1997; 29(9): 458-61. 
21. Schobersberger W, Schmid P, Lechleitner M, et al. Austrian Moderate Altitude Study 2000 (AMAS 2000). The effects of moderate altitude $(1,700 \mathrm{~m})$ on cardiovascular and metabolic variables in patients with metabolic syndrome. Eur J Appl Physiol 2003; 88(6): 506-14.

22. Boyer SJ, Blume FD. Weight loss and changes in body composition at high altitude. J Appl Physiol 1984; 57(5): 1580-5.

23. Simler N, Grosfeld A, Peinnequin A, et al. Leptin receptor-deficient obese Zucker rats reduce their food intake in response to hypobaric hypoxia. Am J Physiol Endocrinol Metab 2006; 290(3): E591-7.

24. Yingzhong Y, Droma Y, Rili G, et al. Regulation of body weight by leptin, with special reference to hypoxia-induced regulation. Intern Med 2006; 45(16): 941-6.

25. Grosfeld A, Andre J, Hauguel-De Mouzon S, et al. Hypoxiainducible factor 1 transactivates the human leptin gene promoter. J Biol Chem 2002; 277(45): 42953-7.

26. Azevedo JL, Jr., Carey JO, Pories WJ, et al. Hypoxia stimulates glucose transport in insulin-resistant human skeletal muscle. Diabetes 1995; 44(6): 695-8.

27. N.N. Arbeiten in sauerstoffreduzierter Atmosphäre [Work in Oxygen Reduced Atmosphere]. In: Luzern / Switzerland, SUVA (Schweizer Unfallversicherungsanstalt), 2009: 7.

28. Gunga HC, Kirsch K, Rocker L, et al. Time course of erythropoietin, triiodothyronine, thyroxine, and thyroid-stimulating hormone at 2,315 m. J Appl Physiol 1994; 76(3): 1068-72.

29. Sakata S, Shimizu S, Kishi T, et al. Correlation between erythropoietin and lactate in humans during altitude exposure. Jpn J Physiol 2000; 50(2): 285-8.

30. Milledge J, Kupper T. Consensus Statement of the UIAA Medical Commission Vol.13: People with Pre-Existing Conditions Going to the Mountains. 2008 [cited 2008; Available from: www.theuiaa.org/medical advice.html.

31. Jean D, Leal C, Meijer H. Consensus Statement of the UIAA Medical Commission Vol.12: Women Going to Altitude. 2008 [cited 2008 11.1.09]; Available from: www.theuiaa.org/medical advice.html.

32. Jean D, Leal C, Kriemler S, et al. Medical recommendations for women going to altitude. High Alt Med Biol 2005; 6(1): 22-31.

33. Meijer HJ, Jean D. Consensus Statement of the UIAA Medical Commission Vol.9: Children at Altitude. 2008 [cited 2008 11.1.09]; Available from: www.theuiaa.org/medical advice. html.

34. Hochstrasser J, Nanzer A, Oelz O. Altitude edema in the Swiss Alps. Observations on the incidence and clinical course in 50 patients 1980-1984. Schweiz Med Wochenschr 1986; 116(26): 866-73.

35. Bircher HP, Eichenberger U, Maggiorini M, et al. Relationship of mountain sickness to physical fitness and exercise intensity during ascent. J Wild Med 1994; 5(4): 302-11.

36. Basnyat B, Lemaster J, Litch JA. Everest or bust: a cross sectional, epidemiological study of acute mountain sickness at 4243 meters in the Himalayas. Aviat Space Environ Med 1999; 70(9): 867-73.

37. Hackett PH, Rennie D. Rales, peripheral edema, retinal hemorrhage and acute mountain sickness. Am J Med 1979; 67(2): 214-8.

38. Maggiorini M, Buhler B, Walter M, et al. Prevalence of acute mountain sickness in the Swiss Alps. Bmj 1990; 301(6756): 853-5.

39. Schneider M, Bernasch D, Weymann J, et al. Acute mountain sickness: influence of susceptibility, preexposure, and ascent rate. Med Sci Sports Exerc 2002; 34(12): 1886-91.

40. Sui GJ, Liu YH, Cheng XS, et al. Subacute infantile mountain sickness. J Pathol 1988; 155(2): 161-70.
41. Arregui A, Leon-Velarde F, Cabrera J, et al. Migraine, polycythemia and chronic mountain sickness. Cephalalgia 1994; 14(5): 339-41.

42. Bernardi L, Roach RC, Keyl C, et al. Ventilation, autonomic function, sleep and erythropoietin. Chronic mountain sickness of Andean natives. Adv Exp Med Biol 2003; 543: 16175.

43. Curran LS, Zhuang J, Sun SF, et al. Ventilation and hypoxic ventilatory responsiveness in Chinese-Tibetan residents at 3,658 m. J Appl Physiol 1997; 83(6): 2098-104.

44. Ge RL, Helun G. Current concept of chronic mountain sickness: pulmonary hypertension-related high-altitude heart disease. Wilderness Environ Med 2001; 12(3): 190-4.

45. Leon-Velarde F, Reeves JT. International consensus group on chronic mountain sickness. Adv Exp Med Biol 1999; 474: 351-3.

46. Monge CC, Arregui A, Leon-Velarde F. Pathophysiology and epidemiology of chronic mountain sickness. Int J Sports Med 1992; 13 Suppl 1: S79-81.

47. Moore LG, Niermeyer S, Zamudio S. Human adaptation to high altitude: regional and life-cycle perspectives. Am J Phys Anthropol 1998; Suppl 27: 25-64.

48. Kupper T, Gieseler U, Angelini C, et al. Consensus Statement of the UIAA Medical Commission Vol.2: Emergency Field Management of Acute Mountain Sickness, High Altitude Pulmonary Oedema, and High Altitude Cerebral Oedema. 2008 [cited 2008 11.1.09]; Available from: www.theuiaa. org/medical advice.html.

49. Küpper T, Gieseler U, Milledge J. Consensus Statement of the UIAA Medical Commission Vol.3: Portable Hyperbaric Chambers. 2008 [cited 2008; Available from: www.theuiaa. org/medical advice.html.

50. Siedenburg J. Kompendium Reisemedizin und Flugmedizin. 6. Aufl. ed. Norderstedt: BoD - Books on Demand; 2009.

51. Kupper T. Non-traumatic aspects of sport climbing. Wien Med Wochenschr 2005; 155(7-8): 163-70.

52. N.N. The Criteria Committee of the New York Heart Association. Diseases of the Heart and Blood Vessels: Nomenclature and Criteria for Diagnosis. In: N.N., Editor. The Criteria Committee of the New York Heart Association. Diseases of the Heart and Blood Vessels: Nomenclature and Criteria for Diagnosis. Boston, Mass.: Little Brown, 1928.

53. N.N. The Criteria Committee of the New York Heart Association. Nomenclature and Criteria for Diagnosis of Diseases of the Heart and Great Vessels. In: N.N., Ed. The Criteria Committee of the New York Heart Association. Nomenclature and Criteria for Diagnosis of Diseases of the Heart and Great Vessels, Boston, Mass.: Little, Brown \& Co; 1994, p. 253-6.

54. Miller-Davis C, Marden S, Leidy NK. The New York Heart Association Classes and functional status: what are we really measuring? Heart Lung 2006; 35(4): 217-24.

Received: March 23, 2010

Accepted: March 26, 2010

Published: March 31, 2010

Adress for correspondence:

Thomas Küpper, Ass. Prof., MD

Institute for Occupational and Social Medicine

RWTH Aachen Technical University

Pauwelsstr. 30

52074 Aachen

Germany

tkuepper@ukaachen.de

Fax: +49-(0)3222-1485489

\begin{tabular}{llll}
\hline Authors' contribution & B - Data Collection & D - Data Interpretation & F - Literature Search \\
A - Study Design & C - Statistical Analysis & E - Manuscript Preparation & G - Funds Collection
\end{tabular}

